\title{
Allelopathic effect of Celtis australis on germination and growth parameters of some important food crops of the Garhwal Himalayas
}

\section{Neha*}

College of Forestry (VCSG, Uttarakhand University of Horticulture and Forestry) Ranicauri, Tehri -Garhwal (Uttarakhand), India

V.P. Khanduri

College of Forestry (VCSG, Uttarakhand University of Horticulture and Forestry) Ranicauri, Tehri -Garhwal (Uttarakhand), India

R.S. Bali

College of Forestry (VCSG, Uttarakhand University of Horticulture and Forestry) Ranicauri, Tehri -Garhwal (Uttarakhand), India

Pravin Rawat

Forest Research Institute, Dehradun (Uttarakhand), India

Ram Gopal

Forest Research Institute, Dehradun (Uttarakhand), India

*Corresponding author. E-mail: neha.pant55555@gmail.com

\begin{abstract}
Present study was conducted to assess the allelopathic effect of leaf and bark aqueous extracts of Celtis australis on Triticum aestivum, Hordeum vulgare, Brassica rapa, Lens culinaris and Vigna umbellate under In-vitro condition. Different leaf and bark aqueous extracts $5 \%, 10 \%$, and $15 \%$ were used to irrigate the seeds of test crops. The results revealed that the concentration dependent significant $(p=0.05)$ inhibitory effect of aqueous leaf and bark extracts on germination, root and shoot length of all the test crops. Among all the test crops Triticum aestivum was found most sensitive where the germination percentage was reduced down to $46.0 \%$ by the leaf extract $(15 \%)$ as compared to control $(82.3 \%)$, while the maximum inhibition in the root length of Lens culinaris $(0.5 \mathrm{~cm})$ by $10 \%$ leaf extract was observed as compare to control $(8.2 \mathrm{~cm})$. In shoot length maximum inhibitory effect was observed in Hordeum vulgare $(3.5 \mathrm{~cm})$ as compared to control $(13.3$ $\mathrm{cm}$ ). Similarly, the bark extract showed the maximum inhibition in germination percentage of Lens culinaris $(41.6 \%)$ at $15 \%$ concentration as compare to control $(70.0 \%)$ while the maximum inhibition for the root length was recorded in Triticum aestivum $(1.9 \mathrm{~cm})$ at $15 \%$ concentration as compare to control $(17.3 \mathrm{~cm})$. In shoot length maximum inhibition was observed for Triticum aestivum $(1.3 \mathrm{~cm})$ at $10 \%$ extract level as compare to control $(13.4$ $\mathrm{cm}$ ), while Vigna umbellate $(5.5 \mathrm{~cm})$ at $15 \%$ concentration showed stimulatory effect as compare to control $(3.4 \mathrm{~cm})$ exceptionally. Finally, it is concluded that Vigna umbellate exhibited the maximum tolerance against leaf and bark aqueous and might be a better option for intercropping with $C$. australis. However, the allelopathic effect on the other test crops can be minimized by removing the fallen leaves from the agricultural fields.
\end{abstract}

Keywords: Agricultural crops, Allelopathy, Bioassay, Leaf leachate, Tree crops.

\section{Article Info}

DOI:10.31018/jans.v10i3.1832

Received: July 18, 2018

Revised: August 11, 2018

Accepted: August 19, 2018

\section{How to Cite}

Neha et al. (2018)

Allelopathic effect of Celtis australis on germination and growth parameters of some important food crops of the Garhwal Himalayas. Journal of Applied and Natural Science, 10(3): $1003-1010$

\section{INTRODUCTION}

The term "Allelopathy" is derived from two Greek words 'Allelon' means each other and 'Pathos' means to suffer, thus, the injurious effect of one plant on other is known as allelopathy. It is the direct influence of various chemicals released from one plant on the growth and development of another plant (Mafeo and Mashela, 2010). Molish (1937) coined the term "allelopathy" which refers to all biochemical interactions either stimulatory or inhibitory among plants, including microorganisms. The higher plants (tree crops) are supposed to release some phytotoxins into soil, which adversely affect the germination and yield of inter crops (Harborne, 1977). The effect of these phytotoxins called allelochemicals was observed more pronounced in early growth stages during germination, radical and plumule emergence (Rawat et al.,2017). The presence of these allelochemicals in the plant part extract inhibits the cell division and which further affect meristematic tissues in growing tip of roots adversely (Rietjens and Alink 2003). Similarly the inhibitory effect of the higher plants on various agricultural crops has been re- 
ported by the leaf aqueous extract of Tectona grandis on stem and root of black gram and green gram (Manimegalai, 2012) and germination and seedling growth of Raphanus sativus by walnut leaf extract (Bahuguna et al., 2013). These allelochemicals can also persist in the soil for long time and can affect both neighboring plants as well as those planted in succession as an intercrop in next cropping season. Although the allelochemicals derived from plants may be more biodegradable than traditional herbicides but may also have undesirable effects on non-targeted species.

Celtis australis Linn. belongs to family Ulmaceae is an important multipurpose tree species which is usually grown in various traditional agroforestry systems in or around agricultural fields in rainfed agriculture of Kumaon and Garhwal region of Uttarakhand. It is commonly grown for fodder, fuel, timber and plays an important role to enhance socioeconomic structure of local people specially by supplying highly palatable, nutritious and tannin-free green fodder particularly during deficit period of green fodder (Yadav and Bisht, 2013). The timber quality of Celtis australis is excellent. It is used in making tools, handles, cups, spoons, oars, canoes, stick and agricultural implements (Bhatt and Verma, 2002). Besides having many advantages as a component in traditional agroforestry system, it is expected to release some chemicals (allelochemicals) either through stem flow or its litter decomposition and affect the intercrop adversely. So, our study is an attempt to evaluate the allelopathic potential of Celtis australis on various traditional field crops of Garhwal Hiamalays viz. Triticum aestivum, Hordeum vulgare, Brassica rapa, Lens culinaris and Vigna umbellate.

\section{MATERIALS AND METHODS}

Present study was conducted at the College of Forestry (V.C.S.G. Uttarakhand University of Horticulture and Forestry) Ranichauri, Tehri Garhwal, Uttarakhand, having geo-coordinates $30^{\circ} 15^{\prime} \mathrm{N}$ latitude and $78^{\circ} 30^{\prime} \mathrm{E}$ longitude at an altitude of about 2100 meter above mean sea level. The metrological data collected from the observatory of College of Forestry, Ranichauri Campus, showed the mean monthly maximum and minimum temperature during the study period (August, 2015 to March, 2016) ranges between $22.8^{\circ} \mathrm{C}$ to $2.0^{\circ} \mathrm{C}$ and annual rainfall between 1.2 to $197 \mathrm{~mm}$. The fresh leaves and bark of Celtis australis were collected from ten trees at Forestry Nursery Block and the seeds of five agricultural crops were obtained from Department of Agriculture and Seed Science of College of Forestry Ranichauri. Then the healthy leaves and bark were dried at room temperature $\left(25 \pm 2^{\circ} \mathrm{C}\right.$ and grinded in mechanical grinder. To prepare leaf and bark aqueous extract $25 \mathrm{~g}, 50 \mathrm{~g}$ and $75 \mathrm{~g}$ of dry leaf and bark powder was soaked in $500 \mathrm{ml}$ of distilled water for 24 hours at room temperature. The resultant solution was filtered with a three layers of Whatman filter paper no.1 and stored in a conical flask (Bhatt and Singh, 2009). The germination trial was conducted in laboratory condition, 25 seeds of each test crop were placed in a petri dish (9 cm diameter) and kept in a germinator at $25 \pm 2^{\circ} \mathrm{C}$. Thus, there were four treatments of dry leaf extract of $C$. australis viz., $\left(\mathrm{T}_{1}=0 \%\right.$ (Control), $\mathrm{T}_{2}=5 \%, \mathrm{~T}_{3}=10 \%, \mathrm{~T}_{4}=15 \%$ concentration of leaf aqueous extract) and four treatments of the bark extract $\left(\mathrm{T}_{1} 0 \%\right.$ (Control) $\mathrm{T}_{2}=5 \%, \mathrm{~T}_{2}=$ $10 \%$ and $\mathrm{T}_{3}=15 \%$ bark aqueous extract) replicated three times. To moistened the petri dishes $1 \mathrm{ml}$ of aqueous extract or distilled water was added in the respective treatment. The experiment extended over a period till last seed germination (8 days), the seed was considered as germinated when the radical emerged out. Finally, the shoot and root length of 10 randomly selected seedlings from each replication was measured at the end of experiment. Then mean germination time was calculated by following formula given by Ellis and Roberts (1981) as: Mean Germination Time (MGT) and Germination Index (GI) were calculated by the following formulae:

MGT $=\sum D_{n} / \sum n$... Eq. 1

where $n=$ no of seeds germinated on day $D(D$ representing the no of days since the sowing of seeds

Germination Index (GI) was calculated by following formula given by Kendrick and Frankland (1969), as:

Germination Index $(\mathrm{GI})=$

Total germination percent

Tỉme (hours)taken for $50 \%$ germination

... Eq. 2

The experimental design adopted for present study was Complete Randomized Block Design and the data was analyzed by using software MSExcel and STPR - 3.

\section{RESULTS}

Wheat (Triticum aestivum): The leaf and bark extract of Celtis australis showed concentration dependent inhibitory effect on germination of wheat. Maximum germination percentage was recorded in control $(82.3 \%)$, while minimum in the seeds treated with $15 \%$ leaf extract (Table 1 ). Similarly, the germination percentage was also reduced significantly $(50.3 \%)$ by the bark extract of $15 \%$ concentration as compared to control (Table 3). The significant inhibitory effect of leaf extract was observed on root and shoot length of wheat. Maximum root length $(17.3 \mathrm{~cm})$ and shoot length $(13.4 \mathrm{~cm})$ were recorded in control treatment while minimum root length $(2.2 \mathrm{~cm})$ and 


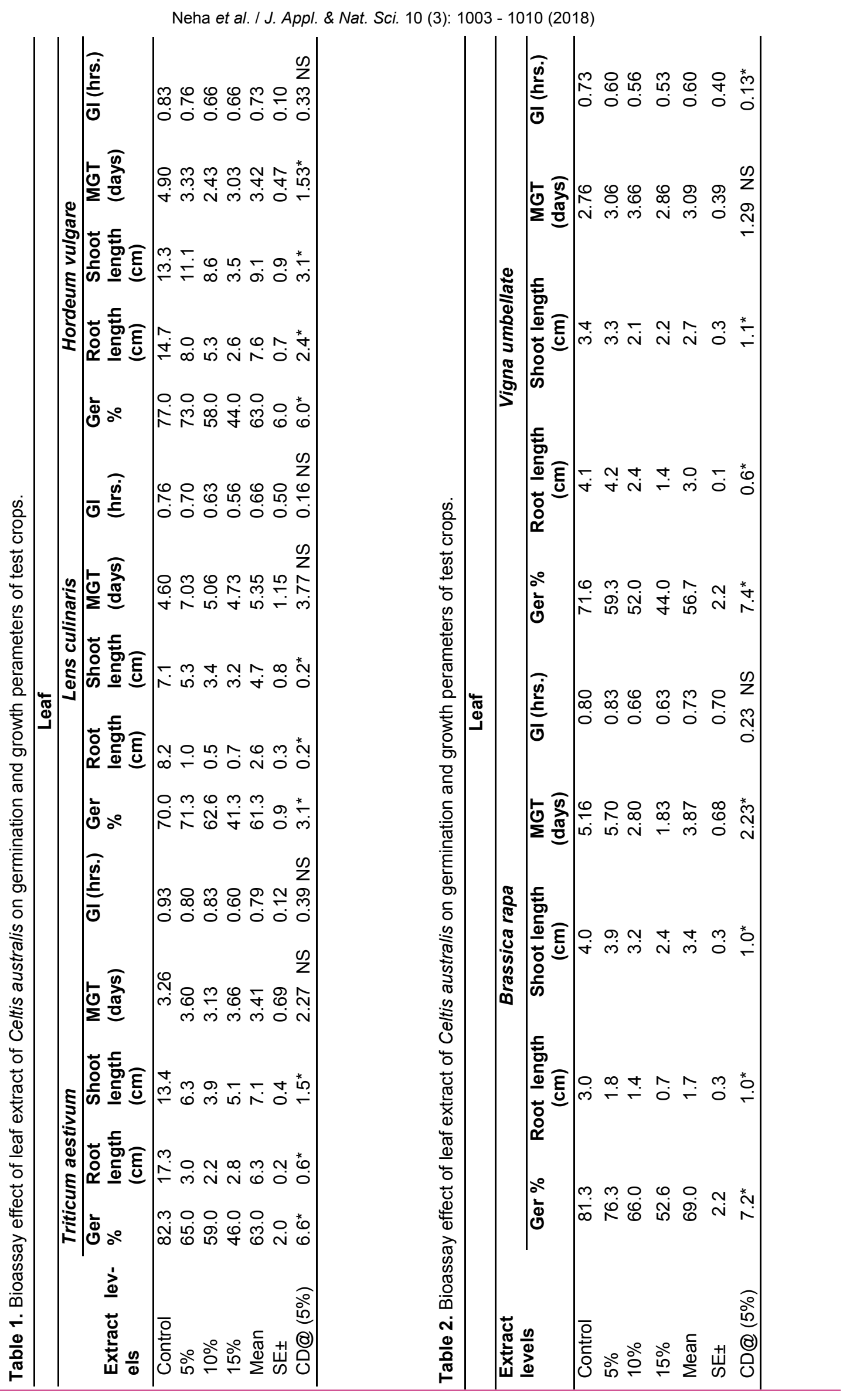




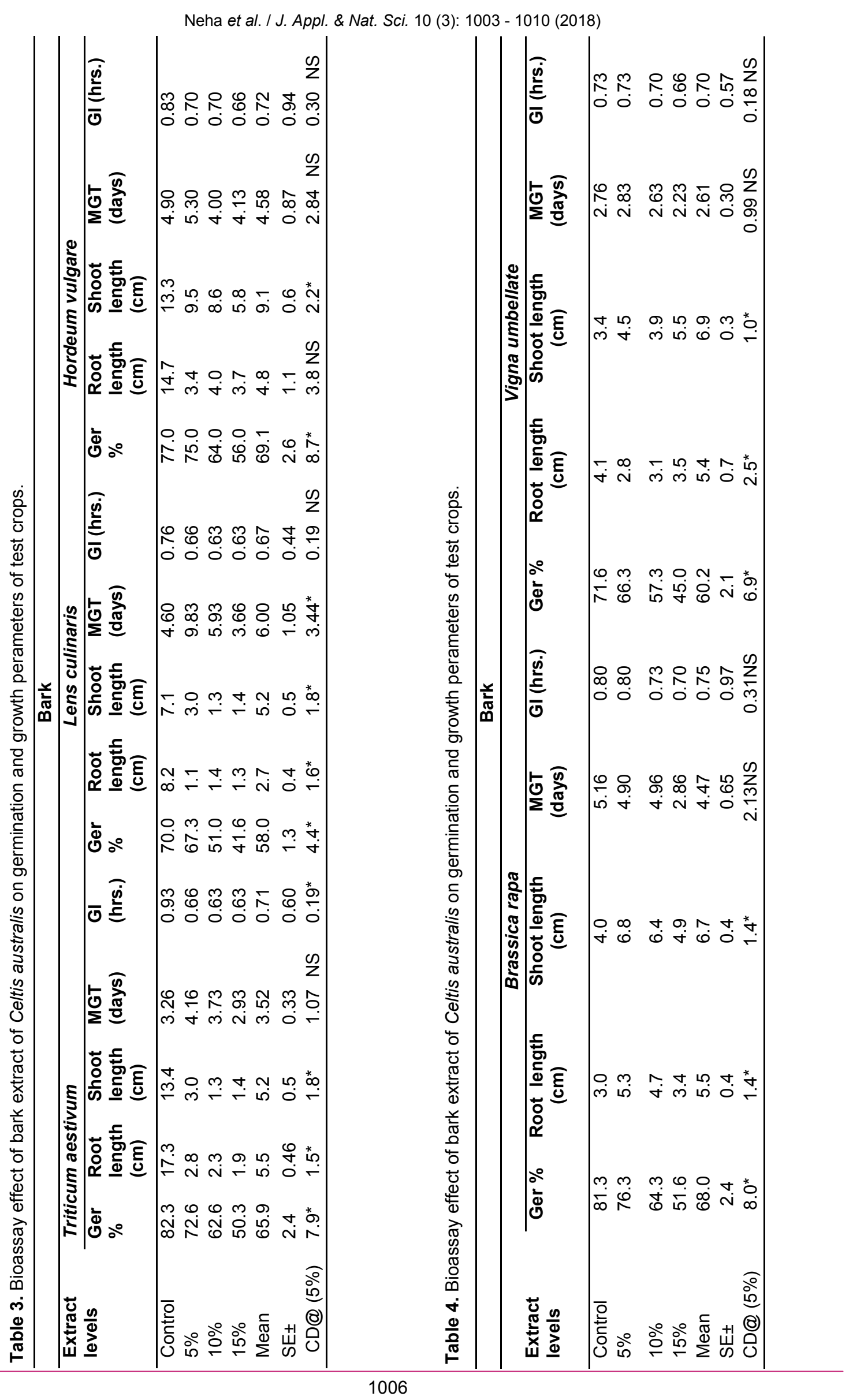


shoot length $(3.9 \mathrm{~cm})$ were found in the treatment of $10 \%$ leaf extract (Table 1). Similarly, in bark extract significant inhibitory effect was recorded. Maximum root length $(17.3 \mathrm{~cm})$ and shoot length $(13.4 \mathrm{~cm})$ were recorded in control while minimum root length $(1.9 \mathrm{~cm})$ in the treatment of $10 \%$ bark extract and shoot length $(1.3 \mathrm{~cm})$ recorded in $15 \%$ bark extract (Table 3 ). The effect of all the concentration of aqueous extract had no significant effect on MGT and GI. In leaf extract maximum value of MGT (3.66 days) was recorded in $15 \%$ leaf extract whereas minimum value of MGT $(3.13$ days) noted in $10 \%$ leaf extract. Similarly in GI maximum value ( 0.93 hours) was recorded in control while minimum value $(0.60$ hours) showed in $15 \%$ bark extract (Table 1). In bark extract lower concentration $5 \%$ and $10 \%$ had stimulatory effect on MGT 4.16 days and 3.73 days compared to control 3.26 days. However the results were nonsignificant. In case of $\mathrm{Gl}$ as concentration increased the significant inhibitory effect was recorded. Maximum value of $\mathrm{Gl}$ (0.93 hours) was recorded in control while minimum value $(0.66$ hours) was noted in $5 \%$ concentration level (Table 3).

Lentil (Lens culinaris): In crop lentil, results show significant stimulation at lower concentration in germination percentage. Maximum germination was observed $(71.3 \%)$ at $5 \%$ leaf extract while minimum $(41.3 \%)$ in $15 \%$ leaf extract (Table 1$)$. In case of bark extract significant inhibitory effect was observed as the concentration level was increased. Maximum germination $(\mathbf{7 0 . 0 \% )}$ was found in control treatment, whereas, minimum germination percentage $(41.6 \%)$ in $15 \%$ concentration level (Table 3 ). The root and shoot length of lentil were significantly reduced towards negative impact of leaf extract. Maximum root length $(8.2 \mathrm{~cm})$ and shoot length $(7.1 \mathrm{~cm})$ were recorded in control treatment, while, minimum shoot length $(3.2 \mathrm{~cm})$ in $15 \%$ leaf extract. The root length $(0.5$ $\mathrm{cm})$ was found minimum in $10 \%$ leaf extract (Table 1). The results revealed significant inhibitory effect in root length and shoot length. In bark extract maximum root length $(8.2 \mathrm{~cm})$ and shoot length $(7.1 \mathrm{~cm})$ length were found in control treatment, whereas, minimum root length $(1.1 \mathrm{~cm})$ in $5 \%$ bark extract and shoot length $(1.3 \mathrm{~cm})$ in $10 \%$ bark extract (Table 3 ). In leaf extract nonsignificant results were obtained in case of MGT and $\mathrm{GI}$. Maximum value of MGT (7.03 days) was noted in $5 \%$ extract level while minimum value of MGT (4.60 days) in control. In GI maximum value ( 0.76 hours) was noted in control whereas minimum value of $\mathrm{GI}$ (0.56 hours) was noted in $15 \%$ leaf extract (Table 1). In bark extract maximum value of MGT (9.83 days) was recorded in $5 \%$ concentration while minimum value of MGT (3.66 days) was observed in $15 \%$ extract level, However results was significant. No significant results were obtained in $\mathrm{GI}$. Maximum value ( 0.76 hours) was recorded in control while minimum value ( 0.63 hours) was noted in $10 \%$ and $15 \%$ extract level respectively (Table 3 ).

Barley (Hordeum vulgare): In barley, similarly increase in concentration significantly influence germination percentage. Maximum germination percentage $(77 \%)$ was recorded in control treatment while minimum germination $(44 \%)$ in $15 \%$ concentration level (Table 1). Considering in bark extract germination percent was significantly reduced. Maximum germination $(77.0 \%)$ exhibit in control treatment while minimum germination percentage $(56 \%)$ was recorded in $15 \%$ bark extract (Table 3 ). In leaf extract there is a significant reduction observed in both root and shoot length. Maximum root length $(14.7 \mathrm{~cm})$ and shoot length $(13.3 \mathrm{~cm})$ were recorded in control treatment while minimum root length $(2.6 \mathrm{~cm})$ and shoot length $(3.5 \mathrm{~cm})$ were recorded in $15 \%$ extract level (Table 1). In bark extract non-significant results was obtained in case of root length whereas significant inhibitory results was noted in shoot length. Maximum root length $(14.7 \mathrm{~cm})$ and shoot length $(13.3 \mathrm{~cm})$ were noted in control treatment and minimum root length $(3.4 \mathrm{~cm})$ in $5 \%$ concentration level while shoot length $(5.8 \mathrm{~cm})$ was recorded in $15 \%$ extract level respectively (Table 3 ). Maximum value of MGT (4.90 days) was observed in control while minimum value of MGT $(2.43$ days) was recorded in $10 \%$ leaf extract. However the result was significant. Non-significant results were noted in case of $\mathrm{Gl}$. Maximum value of $\mathrm{Gl}$ ( 0.83 hours) was recorded in control whereas minimum value of $\mathrm{Gl}$ (0.66 hours) obtained in $10 \%$ and $15 \%$ concentration respectively (Table 1$)$. In bark extract no significant outcomes were recorded towards negative influence of increased extract level in respect of MGT and GI. Maximum value of MGT (5.30 days) was noted in $5 \%$ concentration while minimum (4.00 days) in $10 \%$ concentration whereas the maximum value of $\mathrm{Gl}$ ( 0.83 hours) was recorded in control and $\mathrm{Gl}(0.66$ hours) were noted in $15 \%$ concentration (Table 3 ).

Toria (Brassica rapa): The effect of leaf extract on germination percent of Brassica rapa revealed that as increasing in the concentration of aqueous leaf extract contains decreasing effect on germination percentage. The germination percentage was observed maximum in control $(81.3 \%)$ and minimum $(52.6 \%)$ in $15 \%$ concentration. However significant results was observed (Table 2). In bark extract results indicated significant reduction towards increasing concentration. Maximum germination percent was recorded in control treatment (81.3), while minimum germination percent $(51.6 \%)$ was recorded in $15 \%$ concentration (Table 4). The increased concentration shows significant inhibitory effect on root and shoot length in leaf extract. Maximum root length (3.0 
$\mathrm{cm}$ ) and shoot length (4.0) were recorded in control treatment while minimum root length $(0.7 \mathrm{~cm})$ and shoot length $(2.4 \mathrm{~cm})$ were recorded in $15 \%$ concentration (Table 2). The stimulatory effect were observed in bark when the concentration was increased and the results exhibit significant stimulation. Maximum root length $(5.3 \mathrm{~cm})$ and shoot length $(6.8 \mathrm{~cm})$ were observed in $5 \%$ concentration while minimum root length $(3.0 \mathrm{~cm})$ and shoot length $(4.0 \mathrm{~cm})$ were recorded in control (Table 4). Maximum value of MGT (5.70 days) was observed in $5 \%$ concentration while minimum value of MGT (1.83 days) in 15\% concentration and $\mathrm{GI}$ ( 0.83 hours) in $5 \%$ concentration and $\mathrm{GI}$ ( 0.63 hours) was noted in $15 \%$ concentration Significant results were obtained in case of MGT whereas $\mathrm{Gl}$ shows non-significant results (Table 2). In bark extract, the effect of all concentration had no significant effect on MGT and GI. Maximum value of MGT (5.16 days) was observed in control while minimum value of MGT (2.86 days) was recorded in $15 \%$ concentration and maximum value of $\mathrm{GI}(0.80$ hours) was recorded in control and $5 \%$ concentration respectively while minimum value of $\mathrm{GI}$ ( 0.70 hours) was noted in $15 \%$ concentration (Table 4).

Ricebean (Vigna umbellate): In case of ricebean proportionate significantly inhibitory effect observed on germination as increased concentration of leaf aqueous extract. Maximum germination $(71.6 \%)$, was found in control treatment while the reduction in germination percentage $(44.0 \%)$ was analyzed in $15 \%$ concentration (Table 2 ). Similarly in bark extract significant reduction in germination percentage was observed. Maximum germination percent $(71.6 \%)$ was recorded in control whereas minimum germination percent $(45.0 \%)$ was recorded in $15 \%$ concentration (Table 4 ).

In case leaf extract significant stimulatory effect found in root length whereas significant inhibitory effect recorded in shoot length. Maximum root length $(4.2 \mathrm{~cm})$ and shoot length $(3.4 \mathrm{~cm})$ was found in $5 \%$ concentration and control treatment while minimum root length $(1.4 \mathrm{~cm})$ and shoot length $(2.1 \mathrm{~cm})$ were analyzed in $15 \%$ concentration and $10 \%$ concentration respectively (Table 2 ). Similarly, in bark extract significantly inhibition was found in root length and stimulation in shoot length respectively. Maximum root length $(4.1 \mathrm{~cm})$ found in control and shoot length $(5.5 \mathrm{~cm})$ in $15 \%$ concentration. Whereas minimum root length $(2.8$ $\mathrm{cm}$ ) recorded in 5\% concentration and shoot length $(3.4 \mathrm{~cm})$ in control (Table 4$)$. The results depicted no significant effect was found towards different concentration level. Maximum value of MGT (3.66 days) was observed in 10\% concentration and while minimum value of MGT (2.76 days) noted in control and maximum value of $\mathrm{Gl}(0.73$ hours) recorded in control while minimum value of GI (0.53 hours) in $15 \%$ concentration. However the results was non-significant. (Table 3 ). The MGT and GI were not significantly affected by different concentration of bark extract maximum value of MGT (2.83 days) was observed in $5 \%$ concentration while minimum value of MGT $(2.23$ days) found in $15 \%$ concentration and maximum value of $\mathrm{GI}$ ( 0.73 hours) were recorded in control and $5 \%$ respectively while minimum value of $\mathrm{GI}$ ( 0.66 hours) was noted in $15 \%$ concentration (Table 4).

\section{DISCUSSION}

In present findings in general the leaf and bark extract of Celtis australis showed a concentration dependent inhibitory effect on germination percentage as compared to control treatment except in Lens culinaris, where stimulatory effect was observed in leaf extract. The results observed attributed to the presence of various allelochemicals in leaf as well as bark aqueous extract.

The effect of these allelochemicals of leaf and bark extract varied with concentration of leaf as well as bark extract and the tolerance level of various test crops. The tolerance level of these test crops towards the allelopathic effect of aqueous leaf extract on germination was in following order: Triticum aestivum $>$ Hordeum vulgare $>$ Lens culinaris > Vigna umbellate > Brassica rapa, whereas in case of bark extract Lens culinaris > Triticum aestivum > Vigna umbellate >Brassica rapa > Hordeum vulgare. Present findings are in line with Bhatt and Todaria (1990) they had also reported the inhibitory effect of leaf extract of Adina cardifolia, Alnus nepalensis and celtis australis on germination percentage of Hordium vulgare and Eleusine coracana. ). (Kaushal et al. 2011) also found the inhibitory effect of leaf extract of Morus alba, Grewia optiva, Toona ciliata and Populus deltoids on germination of chickpea, wheat, maize, bean and soyabean. Similarly, the concentration dependent inhibitory effect of Dendrocalamus stocksii leaf leachates on germination of finger millet has been reported (Rawat et al. 2017. The aqueous leaf extract of Aquilaria malaccensis, Michelia champaca, Tectona grandis, Trema orientalis was also reduced down the germination percentage of Oryza sativa, Zea mays, Vigna radiata, Vigna umbellata, and Archis hypogea. In general, the concentration dependent significant $(p=0.05)$ reduction was observed in root length of Triticum aestivum, Hordeum vulgare, Lens culinaris by both leaf and bark extract however, the significant stimulatory effect was observed in the root of Vigna umbellata and Brassica rapa. The inhibition in root and shoot length of test crops might be due to the presence of various allelochemicals in the aqueous leaf and bark extract of C. australis. However, its effect was concentration dependent and acted differently on root and shoot length of various test crops. These allelo- 
chemicals damage the cell membrane of receptor plant (Rice 1984) which further might reduce down the root and shoot length of receptor plant. In present study it was found that the roots of Lens culinaris are more sensitive to allelopathic extracts instead of other parts of plants because they are the first to come in contact with allelochemicals. Similar findings were also reported by Kulkarni et al.2014, where they found root growth of paddy and ragi crops was significantly affected by the leaf extract of Mangifera indica. In case of shoot length significant inhibitory effect was recorded in leaf and bark extract of $C$. australis on all the test crops except in Brassica rapa and Vigna umbellate where, the stimulatory effect of all the concentration of bark extract showed the stimulatory effect. The inhibitory effect of leaf extract on shoot length was observed maximum in Hordeum vulgare while minimum on Vigna umbellata. The results observed are attributed to the various allelochemicals presence in leaf aqueous extract of C. australis and plant response to these allelochemicals. Similarly, Bhat et al. (2011) also reported that the leaf and bark aqueous extract of Anogeissus latifolia reduced down the shoot growth of $V$. unguiculata with increasing concentration of extract. Jayakumar and Manikandan (2005) also found the inhibitory effect of Acacia leucopholea on shoot length of viz., Arachis hypogaea (groundnut) and Sorghum vulgare (sorghum) in proportionate manner with increasing concentration. In case of bark aqueous extract these allelochemicals showed the stimulatory effect on shoot length of Brassica rapa and Vigna umbellate (Table 4). These results were also in line with the findings of Thapliyal et al.,( 2008) where they had found that the bark extract was less toxic to germination and radicle growth of Amaranthus caudatus, Echinochola frumentaceae, Lens culinaris as compared to leaf extract. (Kaushal et al., (2011) had also reported that the stimulatory effect of aqueous leachates of Morus alba at lower concentrations on growth of maize and soybean. Singh et al., (2009), recorded that the leaf and bark leachate of Toona hexendra, Ficus subinsica, and Bauhinia purpurea on radicle and plumule growth of Hordeum vulgare, Triticum aestivum and $B$. campestris. Among the test crops Brassica campestris was the most resistant to toxic effects of aqueous extract. Similar findings were also reported by Shruthi et al.2014 where they observed the stimulatory and inhibitory effect of aqueous leaf extract of Azadirachta indica on shoot length of Vigna radiate. According to Thapliyal et al. 2008, the MGT directly showed the quickness of germination if the lower value of Mean Germination Time (MGT) express faster rate of germination while, the Germination Index (GI) is directly correlated with germination percent. Thus, the greater the value of $\mathrm{GI}$, the greater will be the germination percent. In general the non -significant $(p=0.05)$ effect of both the leaf and bark extract of $C$. australis were observed on MGT and $\mathrm{GI}$ of all the test crops. However, in $H$. vulgare and $B$. rapa the significant reduction $(p=0.05)$ in MGT and GI of $V$. umbellate by the aqueous leaf extract of $C$. australis was observed. In $5 \%$ concentration of aqueous leaf extract increased the MGT of Brassica rapa exceptionally (Table 2). In case of bark the $\mathrm{Gl}$ in Triticum aestivum and in Lens culinaris was decreased by the bark extract in significant manner (Table 3) maximum value of GI was noted in control which means the increasing concentration level inhibit the rate of germination with increasing the concentration from $5 \%$ to $15 \%$ slower the germination were observed in test crops which showed the lower the germination. In case of $\mathrm{Gl}$, maximum value noted on control it means that the increasing concentration level inhibit the rate of germination. However, MGT and $\mathrm{Gl}$ express as lower value in the increasing leaf and bark concentration it means that the germination were affected negatively by the leaf and bark extract of $C$. australis in concentration dependent manner. Similar results was also reported by Bahuguna et al. (2013) where they found the inhibitory effect of walnut on radish in respect to GI. Similarly, Thapliyal et al. 2008 also reported that the GI of Echinochloa frumentaceae has been reduced down by the leaf and bark extract of Sapindus mukorossi in an concentration dependent manner. Prasad et al.2010 also observed that the GI of Brassica rapa has been decreased towards the leaf extract of Juglans regia at higher concentration level.

\section{Conclusion}

The present study on the allelopathic effect of leaf and bark aqueous extract of Celtis australis on germination and growth of some important food crops of the Garhwal Himalayas showed that among these, T. aestivum was the most sensitive crop while $V$. umbellate was found the most tolerant against the leaf and bark aqueous extract. The other crops viz., $H$. vulgare, B. rapa and $L$. culinaris was found moderately resistant. Though, our study is preliminary in nature and showed concentration dependent inhibitory effect on germination and growth parameters of all the test crops. In general, $V$. umbellate exhibited the maximum tolerance against leaf and bark aqueous and might be a better option for intercropping with $C$. australis. However, the allelopathic effect on the other test crops can be minimized by removing the fallen leaves from the agricultural fields.

\section{REFERENCES}

1. Bahuguna, A., Chaubey B.K., Nautiyal. M., Bahuguna .S and Singh. B. (2013). Allelopathic possesions of festering walnut leaf on radish (Raphanus 
sativus L.) seed germination and sprout growth in Uttarakhand Himalaya. International Journal of Botany, 9:86-90.

2. Bhat, J. A., Kumar M. and Singh B. (2011). Effect of leaf and bark aqueous extract of Anogeissus latifolia on growth performance of Vigna unguiculata. Agricultural sciences, (2):432-434.

3. Bhatt, B.P. and Singh, J.K. (2009). Allelopathic effect of tree species on crops in Eastern Himalaya, India. Allelopathy Journal 23(2): 333-344.

4. Bhatt, B.P. and Todaria, N.P.(1990). Studies on the allelopathic effect of some agroforestry tree crops of Garhwal, Himalaya, Agroforestry Systems, 12:251256

5. Bhatt, B.P. and Verma, N.P.(2002). Some multipurpose tree species for agroforestry systems, published by ICAR research complex for NEH region, Umiam, Meghalaya: 148.

6. Ellis, R. H. and Roberts, E. H. (1981). The quantification of aging and survival in orthodox seeds. Seed Sci. and Tech. 9:373-329.

7. Harborne, J.B.(1997). Introduction to Ecological Biochemistry.Academic Press, New York.

8. Jayakumar, M.,Manikandan, M. (2005). Allelopathic potential of Acacia leucopholea on groundnut and sorghum. Proceedings of the 4th World Congress on Allelopathy, "Establishing the Scientific Base", Wagga Wagga, New South Wales, Australia, 21-26 pp. 301-306.

9. Kendrick, R. E and Frankland, B. (1969). Photocontrol of germination in Photocontrol of germination in Amranthus caudatus. Planta 85: 326-329.

10.Kulkarni, A., Rathod, R and Hegde H. (2014). Allelopathic effect of various tree species on germination and root growth of crop plants. Journal of tree science 33(1): 61-68.

11.Kaushal, R., Verma, K.S. and Singh, K.N. (2011). Allelopathic effect of important agroforestry tree species of western himalaya on field crops. Journal of Tree Sciences, 30(4): 385-388.

12.Mafeo, T.P. and Mashela, P.W.(2010). Allelopathic inhibition of seedling emergence in dicotyledonous crops by Cucumis bionematicide. African Journal of Biotechnology 9(49): 834-835.

13.Manimegalai A. (2012). Allelopathic effect of Tectona grandis leaves on protein content changes of black gram and green gram. International Journal of Current Sciences, 4: 30-34.

14.Molish, H.(1937). Der Einfluss einer pflanze auf die andere: Allelopathic (Jena: Gustav Fiscer, 1937) : 20

15.Prasad, B., Sah, V.K., and Lavania, S.K. (2010). Effect of Walnut Leaf Extract on Seed Germination and Seedling Vigour of Toria (Brassica rapa L. var. toria)

16.Rawat, P., Narkhede, S.S., Rane, A.D.,Mahiske, V.M. and Dalvi, V.V.(2017). Allelopathic Effect of Leaf Leachates of Solid Bamboo Dendrocalamus stocksii (Munro.) on Growth and Yield of Elusine coracana L. (Gaertn.). Indian Journal of Agroforestry, 19(2): 7982.

17.Rice,E.L.1984. Allelopathy ( $2^{\text {nd }}$ Edition). New York. Academic Press.

18.Rietjens, J.M and Alink, G.M. (2003). Nutrition and health toxic substances in food, Ned Tijdschr Geneeskd. 147: 2365-2370.

19.Shruthi, H.R., Kumar Hemanth, N.K. and Jagannath S. (2014). Allelopathic Potentialities of Azadirachta indica A.Juss. aqueous leaf extract on early seedling growth and biological parameters of Vigna radiate (L.) Wilczek. International Journal of Latest Research in Science and Technology 3(3): 109-115.

20.Singh, B., Jhaldiyal, V. and Kumar, M. (2009).Effects of aqueous leachates of multipurpose trees on test crops. Estonian Journal of Ecology 58 (1):38-46.

21.Thapliyal, S., Bali, R.S., Singh, B., Todaria, N.P. (2008). Allelopathic effect of tree of economic Importance on germination and growth of food crops. Journal of Herb Spices and Medicinal Plants 13(4):11-23.

22.Yadav, R.P. and Bisht, J.K. (2013). Agroforestry: A way to conserve MPTs in North western Himalaya. Journal of Agriculture and Forestry Science, 1(9):8-13 